\title{
Whose Eyes?: Women's Experiences of Changing in a Public Change Room
}

Marianne Clark, MA, Faculty of Physical Education and Recreation, University of Alberta Email: mclark1@ualberta.ca

\section{Abstract}

Fitness and recreation centres populate today's modern urban communities and cater to a wide range of people seeking health, fitness and social connection through physical activity. While women's experiences in these spaces have received some scholarly attention from feminist scholars and scholars of the body, little research has explored women's lived experiences of the change room. In this paper, I argue that everyday spaces such as change rooms and locker rooms are important spaces in which social understandings of the female body manifest. In such spaces, the materiality of the body and the social meanings ascribed to the female body are illuminated and negotiated by those who inhabit and move through them. Using Sartre and Merleau-Ponty as theoretical guides, I discuss how it is for women to see and be seen in a public change room, and how these spaces illuminate the complex relationship women have with their bodies in contemporary society.

\section{Whose Eyes?: Women's Experiences of Changing in a Public Change Room}

I walk into the change room and pace anxiously up and down the rows of lockers. I look for an empty aisle, hoping for some semblance of privacy. I don't like to change in front of others, it makes me uneasy. Perhaps I'm uptight. Or maybe I have what experts would call "body issues." But either way, changing in public causes me stress. I see a change area without anyone in it and feel myself relax a little. I head to the locker at the end, put down my bag, untie my shoes and start to take off my clothes. I practically hold my breath as I slip off my jeans and grab my athletic pants. I perform a careful choreography, a rushed balancing act on one leg, and then the other, as I quickly pull my pants on. I am hurrying, I feel like I'm racing time, hoping that no one comes around the corner at this very minute. I'm halfway done. I face the wall as I lift my shirt over my head. Aware of my exposed back, I glance behind me. Good. Still no one else is there. 
How different changing in a public space is from changing within the privacy of our own homes. Our awareness shifts, our body might become tense, and our heart might beat slightly faster. Whereas at home, we may undress without giving it a second thought. At home, it is routine. Before we retire each night, we undress. Article by article, we remove our clothes from our limbs and uncover our skin. We may crawl into bed wearing pyjamas or we may wear nothing at all depending perhaps on habit, our mood, or the temperature of the season. Then, in the morning, before leaving the house each day, we engage in the reverse act of dressing. Article by article, we cover our skin and adorn our limbs. The clothes we wear conceal our physical nudity or provide a barrier between our naked flesh and the outside world. Yet, generally, we tend to scarcely reflect on these moments of undressing and dressing. They constitute the routine and largely taken-for-granted aspects of our daily existence. If we do give any thought to the act of undressing it may be that we consider which articles to select and lay out for tomorrow. Perhaps we have a special meeting planned and we want to look good. Then, we may attend to the act of dressing with a quick or studied glance in the mirror to make sure things look alright.

What is this experience like in places where we may encounter the presence and look of others however? This may happen, for example, in the public change room of a recreation or fitness facility. In current Western society such places dot our landscapes and decorate the urban grid.. It is no great stretch to say that health has become a societal preoccupation and the body the subject and object of much scrutiny. Therefore, the fitness centre, recreation centre, and even the school gymnasium have become increasingly important spaces in which girls, women, boys and men come to understand and make sense of their physical selves.

\section{Related Literature}

The popular interest in fitness has led some health psychologists and sociologists to examine aspects of fitness settings in detail (Katula, McAuley, Mihalko, \& Bane, 1998; Martin-Ginis, Jung, \& Gauvin, 2003; Walton \& Finkenberg, 2002), as well women's experiences in these settings and in fitness classes (Dworkin, 2003; Markula, 1995; Prichard \& Tiggemann, 2005a). It has been reported that exercising in fitness centre environments is associated with greater body image concern and provides an atmosphere in which women's bodies are on display (Prichard \& Tiggemann, 2005a, 2005b). Furthermore, exercising in mirrored environments has been shown to impair self-efficacy for exercise in women who are usually sedentary (Martin-Ginis, Jung, \& Gauvin, 2003), and to promote self-objectification in some women (Prichard \& Tiggemann, 2005b). The use of mirrors, particularly in traditionally "feminine" physical activities such as aerobics, is thought to increase objectification of female bodies through self-surveillance. Yet those who have studied women's experiences in fitness settings and in other physical activity surroundings say many women enjoy fitness practices although they are at times problematic (Harvon Collins, 2002; Markula, 1995). Aside from concerns about body image, those who exercise have reported experiences of improved body awareness, bodily competence and body confidence, stress release, increased social connection, and feeling mentally and physically better after activity (Crossley, 2004; Haravon Collins, 2002; McDermott, 2000).

Therefore, fitness appears to play an important, if complex, role in girls and women's lives. That is, concerns about not only bodily health but also body self-consciousness are common themes. 
While women's experiences in fitness settings have been explored in some depth, little attention has been paid to the lived experience of changing in the public change room, which most facilities have. However, it is this space, and what happens in this space, that interests me. I have always dreaded changing in these spaces and have even been discouraged from participating in recreation because of my reluctance to do so. For in these places, the body is organized and displayed in a particular way. As Caroline Fusco (2006) writes, "[p]eople shape, and are shaped by this everyday health and fitness space and its discursive and material practices, particularly as they go about their daily work, administration, and play" (p. 68). Although change rooms are taken for granted aspects of the fitness centre, these places require the removal of clothes in spaces that may expose us to strangers' gazes. In these moments of undress, what is experienced? How may a woman in the public change room feel when she undresses her body?

\section{Methodology}

The purpose of this phenomenological inquiry is to explore women's experience of changing in public change spaces. Specifically, the focus was on locker rooms and change rooms in public fitness and recreation settings. The study is grounded inhuman science research (i.e. hermeneutic phenomenology) and is guided by a context-sensitive form of interpretive inquiry (van Manen, 1990). A hermeneutical phenomenology seeks to reveal and interpret the lived experiences one encounters in everyday situations and settings and is concerned with the study of pre-reflective experience, or, how the experience is actually lived rather than how it may be theorized or categorized. Van Manen and Adams (2010) suggest that human science research is not merely a methodology. It ought to be conceptualized as an attitude or a position from which to approach the world one is investigating. This requires the researcher to "turn towards" the phenomenon and necessitates curiosity and reflexivity. Therefore, I found myself reflecting upon my own interest in the topic and examining my own personal experiences. As a woman in today's body conscious society, as a dancer, and as a frequent gym go-er, I often inhabit these very spaces about which I write, or, these spaces that require me to undress (potentially) in front of others. My own embodied and emotional responses to these situations directed me to this topic and have cultivated a curiosity or a sense of persistent wonder about what is it that occurs in these spaces for women who change in them?

To collect material for this phenomenological study, I relied on lived experience descriptions (LEDs). These LEDs can be collected through interviews, observations, dialogue, and literary sources (van Manen, 1997). I drew primarily upon interviews, informal conversations, and my own experiences. LEDs were collected from 6 women aged 18 years and older. All of these women shared in-depth experiences and conveyed a connection with the topic. The goal of phenomenology is to open and explore a human experience rather than to generalize to a population. Therefore empirical sampling procedures are not applicable to phenomenology. My participants were drawn from women I know who belong to fitness and recreation centres or who otherwise had related experiences and memories to share.

In keeping with the tradition of human science inquiry, analysis of interview transcripts was guided by hermeneutic interview reflection (van Manen 1997). This process involved consideration of the four existentials as outlined by van Manen (1997) (i.e., lived time, lived- 
space, lived-body, lived-other). Throughout analysis, attention was paid to the heuristic reduction (van Manen \& Adams, 2010). Heuristic reduction seeks to reveal the extraordinary about what is accepted as ordinary in order to open the phenomenon to curiousity and wonder.

Holistic and line-by-line readings of transcripts were used to reveal and explore the themes of lived experience descriptions. Anecdotes were drawn from the interviews to capture and illustrate the meaning of the lived experience for participants. These anecdotes were created by editing out superfluous material in order to strengthen the stories and focus them towards the phenomenon and identified themes. The first person voice is used throughout as is sometimes done in hermeneutic phenomenological writing. It is used in order to represent both the particular (the single person "I" or me) and the general or shared (the every-person or anyone "I"). This way the boundaries of the singular and shared experience can be transcended. I also chose to blur the lines between myself as the researcher/author, the participant(s) and the reader in order to evoke a richer sense of understanding and resonance for the reader.

\section{Undressing Brings the Body into Awareness}

I'm halfway dressed and continue to hurry. Naked from the waist up. Just as I am about to reach for my athletic top I hear my name: " $M \_$_ is that you?" $M y$ heart sinks. A woman I know through common friends stands in front of a locker two down from mine. I put on my athletic bra before turning around and acknowledging her, forcing myself to be friendly and to act normal. A lot of me is still exposed, my stomach, back, arms. All of a sudden I feel really self-conscious and I can't concentrate on the conversation, I can't seem to act normal. I don't know where to put my eyes. I don't know where her eyes are. What does she see? Did she notice my flabby stomach? I hate my stomach. What is she thinking? I feel that now that she's seen my body naked she knows something about me that she didn't before.... I continue talking with her, trying to appear normal. I am dressed now, but still feeling flustered.

How quickly self-consciousness reappears when clothing is removed, when flesh is exposed and the potential to be seen by another introduced. Just moments before entering the change room, I was rushing about my day, my mind occupied by daily tasks, practically oblivious to the presence and the existence of my body. In fact, the body is usually more or less unnoticed. It comes into focus only when attention is drawn to it such as when hunger pangs well up reminding that lunch hour had come and gone or when a sudden pain strikes the body.

Yet, as the task of undressing was suddenly in front of me, my focus shifted somehow, and I became subtly aware of my body as something that I not only live but also as an aspect of me that may be observed. I became aware of my body in its materiality. I became aware of its fleshiness and of its very being, and understood that, as I undress in public, it becomes something that may be observed by others as well as that which I live. With this realization a sense of detachment may occur. It is as though the body I undress does not completely belong to me in this public space. It is as though I give something away or as if something is taken away from me in the process of undressing. But is that so? And if yes, exactly what is taken away? 
What is it that is exposed in the act of undressing in front of others? What happens when we strip our body of the clothes that we so routinely or carefully put on each day?

Jean Paul Sartre (1956) points out how, in everyday life, we tend not think of our body in terms of its appearance, its functions, or its organs, flesh and bones. Instead, we live our body and experience the world through bodily movements, responses, and interactions with the people and objects around it. Sartre's description of the body as "passed over in silence” (passé sous silence) illuminates how easily we engage in our daily tasks without taking reflective notice of our corporeality. Instead, we are primarily concerned with what we do, where we are going, who we are talking to and what the purpose of any given moment is. Yet, as revealed in the opening anecdote, our awareness of the body can shift. The body comes closer to the foreground as the task of tending to it draws near. When faced with the act of undressing in the locker room, I no longer passed my body over in silence, instead I noticed it differently than moments before. I became aware of it as my physical presence in the enclave of lockers. I became aware of it's shape, the way it occupied space, it's weight. My body was that which I was, but it also took on an aspect of being an "it": some-thing that moved through the space of the locker room. Merleau-Ponty (1962) articulates this tension between having a body and being a body. According to Merleau-Ponty's writings, we are our bodies. We meet others and experience our world first of all through our bodies. The body is both the location from which we form our relationships with the world and other objects in it, as well a phenomenon experienced by the person who lives in it.

In the act of undressing, the body is both lived (experienced) and acted upon. Yet when changing in a public change room, the body may be lived differently than when changing in the privacy of one's home. For in the change room, the potential exists to be seen.

\section{Undressing Disrupts the Embodied Experience of Self}

Sartre describes how we, through the "shock of the encounter with the Other" can recognize our body (that we simply lived just moments before) as an object to be seen and evaluated by the Other. It is as though self-consciousness and a judgmental awareness of the "self" is constituted through the gaze of someone else. "By the mere appearance of the Other, I am put in the position of passing judgment on myself as on an object, for it is as an object that I appear to the Other" (Sartre 1956, p. 189). As I change in the locker room, in the presence of another woman, I suddenly see myself, my body, as though I am outside myself. I see my "self as body" through the other's eyes, as though it is an object to be gazed at. Indeed, in Sartre's account, the body becomes totally objective or a mere thing to be subjected to a gaze. However, even in a change room, where we may encounter the Others' gaze, we can never achieve complete distance or separation from our body. We cannot see our body the way another might. Merleau-Ponty explains this phenomenon and claims our body is not an object from which we can separate ourselves and that we can observe as we can other objects in our world. We cannot act upon our body-object in the same manner as we can act upon other objects. The reason is that our body is our body-subject (corps-sujet). For an object "is an object only insofar as it can be moved away from me... Its presence is such that it entails a possible absence. Now the permanence of my body is entirely different in kind” (1962, p. 90). 
Therefore, we can never see ourselves as another might see us. We can look at our body from various angles, we can explore each limb and crevice, we can see it in parts and also in its totality with the help of the mirror, but we will always also be located within our body. The body is always both observed and lived. Perhaps changing in a public space illuminates this relationship.

I stand in front of my locker wearing only my underwear. I'm still sweating from my workout and I can see moisture beading on my belly, on my arms, feel it trickling down my shins. The air feels refreshing and cool on my hot skin, and I luxuriate in the sensation, take my time getting my shower things ready. Another woman comes into my area and I start, turning away instinctively, covering my breasts. For a minute I see what she sees, me, a middle aged woman standing aimlessly in her underwear, just letting it all hang out. I feel embarrassed and start to move with more purpose and focus on getting dressed, wiping my damp skin with a towel, the sensation of my sweat now feeling sticky and excessive. (Nadine)

Here the body is both lived subject, one that sweats, senses, feels and experiences, as well the object which is gazed upon. In feminist scholar Elizabeth Grosz's (1994) discussion of corporeal phenomenology, she draws from Merleau-Ponty's understanding of the body. For her the body is at once a subject and lived reality for oneself and an object for others. But it is never simply object, nor simply subject. When we undress in a public change room, we experience our body as "I" or "me" and it is that through which our subjectivity unfolds. But at the same time that we live our body, it has the potential to appear as an object to others. The ambivalence of the body is illuminated in this space. The body is neither an interior or an exterior, but always both.

Why is it that the body is experienced differently under the gaze of another? Perhaps in this situation, the relationship between the body and the self is disrupted. For the two are intricately entwined. When I undress, I do not simply undress my body as some object, but the body as the self I understand to be me, I. The body is that from which and through which my understandings of the world are explored and through which the world understands me.

\section{Undressing is to Reveal an Intimate Body-Self}

I'm never very comfortable in the change room, sharing that much of myself with strangers. It's not that I'm not confident in myself, but when people can see my body naked I feel a little vulnerable. (Jennifer)

The notions of "self," "body and "me" are spoken almost interchangeably by Jennifer. As such, her speech resonates with Merleau-Ponty's idea that our "self” is not separate from our "body." The two are in fact intricately involved with and interwoven with each other. As the corporeal body is undressed, so then our intimate sense of ourselves may also be exposed. Without the shield of clothing, being looked at means being seen in a different way. Jennifer suggests that "more" of the self is somehow accessed through the undressed body and that this elicits feelings of vulnerability. 
There is something about our bodies being viewed naked rather than clothed that may rupture our embodied experience of ourselves. Perhaps clothes are experienced as a second skin or as an outer layer of ourselves. Fashion has explored how clothing may assist in giving us a sense of identity: aloof or approachable, severe or relaxed. In summertime warm weather we may choose to dress formally or casually, modestly or daringly, in shorts or in a skirt. We may cultivate our identity through the clothes we wear and through the way we present our body to the world. We may not just cover our body but write upon its surface with make-up, tattoo, body-art and tanning. The observable result of these choices may say something about us and who we are in our lives. They may signify cultural meanings and values we associate and ourselves with and they may influence the way we conduct ourselves with other. In essence, they become part of our embodied self, our identity, as a woman, an athlete, a mother and so on. Yet when we shed our clothes in a public change space, what happens? Consider a stage actress who, in performance, steps wholly into character, embodies the role she has constructed and connects with the audience through the character she portrays. After the performance, in the quiet of her change room, she removes the layers of theatrical makeup from her face, steps out of costume and into her own street clothes. What is the fate of the role she just played? Does she shed that role completely? Similarly, when we shed our clothes, do we lose sense of our carefully cultivated self? Are we somehow different in those moments when we stand there naked?

I angle my body this way and that as I undress and dress in the locker room. I look down to button my pants, I see my small breasts, my protruding stomach, no longer held in, contained and covered by my control top nylons and stylish skirt. This naked me is almost unfamiliar to me, so different than who I am all day, when I march around and am busy and efficient and in charge. But now, as I stand practically naked in the change room, no one can see that part of me, all there is to see is my body. (Melanie)

Perhaps then, the body is always part of our performance on the stage of life. The body is always playing its role in the act of facing others. Although we may shield it or cover it with clothes, we can never remove or close our body from the world or from the knowledge and gaze of other (Levinas, 1969). Therefore, when we undress in the change room, we are slightly transformed. We may surrender an aspect of our identity that we consciously or unconsciously perform as we undress. We may occupy a liminal space if even for a short time. That is, when our body is exposed there is no filter through which the Other might read us. As Anne says, without clothes, "all there is to see is my body." What does the body tell us?

\section{Undressing is to Reveal a Culturally Inscribed Body}

When reduced to biology, the body can be understood as an intricate arrangement of blood, bones, muscles and ligaments organized into complex systems that support our daily life. Yet the body evokes powerful reactions and responses when positioned in its particular socio-historical location. Within this, women's bodies are understood in particular ways. Grosz insists on "the irreducible specificity of women's bodies, the bodies of all women, independent of class, race and history" (Grosz, 1994, p. 207.) The implication of this claim is that women's experiences are 
always already shaped by the fact of their female body and the cultural meanings and processes invested in.

Grosz further explains that women's bodies are marked as different to men's primarily through their reproductive capacity and processes (1994). Indeed, those parts of the body associated with this aspect of the feminine (i.e., the breasts, belly, thighs, and buttocks) evoke some of the most vivid responses from women in their change room stories. These are the body parts that seem to be most intensely noticed, lived, described, lamented, wondered at, admired, abhorred and problematized.

As I pull my shorts off, I give in to knowing that the size and tone of my thighs may not be beautiful by magazine standards, I'm not a supermodel, and most of time I'm ok with it, but sometimes, like now, I'm reminded. I know my thighs were jiggling when I ran on the treadmill, everything was jiggling, but that's what happens when you've got boobs and a butt...(Melanie)

In Melanie's account we can read an acknowledgement of the fact of women's bodies, as well as the cultural understandings written on them. The popular idea of the supermodel aesthetic as an attainable aesthetic intersects with the material reality of what women's bodies really can do and are. Melanie both knows and is "reminded" that as a woman, our very subjectivity is always shaped by our bodies. And the body is never a constant.

I rush to the change room and lock myself in the bathroom, If I change the other girls will see my new bra, my Mum bought it and said I should wear it, but I don't want them to know, I don't want to deal with “developing” yet. (Alyssa)

As Alyssa realizes, the body changes, is full of surprises, it develops, grows, moves and ages. And these changes often occur beyond our control. We may invite these changes or resist them because we may feel as though the body has betrayed us. But because we live our bodies, we experience these changes in complex, embodied ways. The story of the body-self and its life, its vitality, its capacity for expression cannot be understood or comprehended by someone simply gazing upon the body. Jennifer expresses this tension at the end of her story.

I don't care so much about jiggly thighs on the treadmill, or if someone sees me naked in the change room, sometimes I'll just change without trying to hide or turn away, but what I worry about is what they might think when they see me. If they see my saggy parts or my soft parts, I'm worried I might be labelled unfit, unfeminine, lazy or worse. And I want to scream, this isn't the whole story - this does not tell you everything about me! (Jennifer)

What story does the body tell? In Alyssa's case and in Jennifer's case, the body can give away very personal information. The wearing of a bra, the emergence of breasts, can mark a visible shift from a girl's body to a woman's body. With this physical change comes a change in the way one understands and relates to ones' body and oneself, as well as the way we may be read by others. Feminist scholars and scholars of the body and culture have argued that the body, in current neo-liberal society is read according to race, class, and gender (Bordo, 1993; Butler, 
1990; Gard \& Wright, 2005; Schilling, 2003). Via the shape and size of one's body (particularly the female body), one is categorized as either healthy or not-healthy, fit or fat; and degrees of proper femininity and responsible citizenship are assigned accordingly. For example, if one is thin, one is assumed to be healthy, and may be socially rewarded for ascribing to practices that indicate personal responsibility and for complying with historically dominant ideas of normalized femininity. Some scholars are critical of these categories and argue that they essentialize and limit our understandings of what a healthy feminine body is. For example, if desirable, normalized femininity is defined in part by a particular body shape and size. Bodies that do not meet this criteria are excluded from this category and marginalized.

When we see, or are seen by the other, we see through a particular historical, social, and temporal lens. This lens may illuminate and sustain certain ways of understanding the body while overshadowing others. Cultural notions about bodies, health, and identity seep into our understandings of the body and therefore shape the experiences we have within our own. In settings such as a public change room, it may be revealed more clearly to our consciousness that while the body is an organic, material entity, it is also written with social meaning. The shape of one's body, the substance of one's body, the flesh on one's thighs, stomach and breasts becomes meaningful in particular ways and is read in particular ways according to the social and cultural context in which it exists.

\section{Undressing is to Look and to be Looked At}

Yet in today's society, bodies are everywhere to be seen and to be looked at. Indeed, our daily existence is flush with invitations to look and to be looked at (Berger, 1972). Images of partially or wholly naked and sometimes highly sexualized male and female bodies present themselves uninvitedly. They are splashed across billboards. They call to us from music videos and commercials. They beckon us from glossy magazine covers. When we look at these fashionably (un)dressed men and women, when we look them in their eyes, we notice something peculiar. It is, says Van den Berg (1974), as if these faces that look at us really look at themselves. Or rather, they look at themselves through the eye of the camera that took their pictures. As they look at us from these flashy magazines, they simultaneously look at themselves self-consciously through our eyes. Van den Berg considers this self-conscious look a sign of our "divided existence" or as we are now wont to say, our postmodern existence. It is not only these beautiful, partially clad young women and men who know that they are seen though. We all are inhabitants of this world of divided existence.

Sometimes it seems that I see myself as I imagine the "other" sees me. This may happen, even when I am all by myself. As I undress in the privacy of my bedroom, I turn to the wall, turning away from the reflection of the mirror as I undress. In this way I do not look at myself as I would look at another, and I attempt to quiet the feeling of being "looked at." Yet in a change room, it may be difficult to avoid looking and being looked at.

I can't help but look at the woman standing a few lockers away from me, she's wearing nothing but a towel wrapped around her wet hair and I can see everything. I feel like I should avert my eyes, like I'm peeping or something, but it's hard not to 
look. I'm so aware of her body, just a few feet away from me, and even if I don't look at her directly, I'm aware of her presence, of her nakedness and somehow I feel shy. It feels very intimate in a way...like we're sharing something even though we don't talk or know each other. I'm a little in awe...I can't help but think she's beautiful, the way she is so comfortable in her body, and I wish I knew her secret. (Nadine)

Van den Berg (1964) reveals that the second dimension of the body, as argued by Sartre, comes into being under the gaze of the other. He explains, "the word, the gesture, and the look of a fellow man may increase or lessen the distance between man and his body...” (1972, p. 56). Indeed, as Sartre's example of being caught looking through the keyhole illustrates, the gaze of the other may bring our body into sharper focus. In a female public change room, the "Other" is comprised of girls and women. Therefore, it is not the "male gaze," but the female gaze that is encountered. Undressing in front of women is different from undressing in front of men and possibly different yet than the experience of undressing in front of a lover. When we undress in front of a lover, we may welcome and desire his or her gaze. We may want to be seen or to have our body flourishing under our lover's gaze. When undressing in front of a lover, the body may be shared in a gesture of intimacy, offered to the eyes, to the hands, to the body of the other. In this offering too there may be vulnerability, but this vulnerability is more likely chosen or understood as an artifact of the relationship. In contrast, undressing in front of strangers is different still. In public change rooms, undressing is not chosen, but engaged in out of necessity. Bodies stand beside each other in these spaces in various stages of undress. They do not touch each other. In fact care is taken to ensure this.

Yet there may be potential for connection. Perhaps we do "touch" each other with our eyes. Levinas emphasizes the magnitude of the gaze as he maintains that our subjectivity is formed in and through being seen and recognized by the Other. We bear witness to ourselves and express ourselves only as "a face, that is, as speech" (Levinas, 2000, p. 200). When we are face-to-face, we are inevitably in a relationship of sorts and we take the Other into ourselves. Not only do we see the Other with our eyes, but also we sense them with our entire bodily being. In this way the Other senses us. For Levinas (2000) the face of the Other is the way in which the Other is revealed to the self. The face of the Other is the exteriority of its being.

Merleau-Ponty and Levinas presume a type of integration of the senses, where, "the visual resonates with the sayable; the light is capable of eliciting a tactile, textured response, hearing can be visualized (Grosz, 1994, p. 100). So then, when undressed, we perhaps "see," hear and touch each other in different ways than we do when clothed, are faced with an almost palpable potential for closeness. Perhaps the undressed body is not something to be seen, read, or understood, but "somebody responded to."

I like the time in the change room after a workout. I like being in a space where my body is just a body among other bodies. I know people might see me naked or partly naked but it doesn't bother me, this is who I am, this is my body, this is how I am in the world. I like being around all these other women of all shapes and sizes, it makes me feel connected to who I am, and somehow close to them. (Alex) 
It may be that we indeed touch one another in some way when we look into the face of the other. In the presence of others (bodies), one's own subjectivity may be recognized. For, I argue that the (female) body cannot be reduced to a socially constructed entity, or a material object. Instead it is a collection of forces or a source of life and potential. It can be seen, observed, and touched as it can also touch and see. It is not still or fixed. It moves and feels and sees. Perhaps, through movement, touch, sight, and sound the body negotiates the physical and social spaces in which it finds itself. Perhaps the body when it is seen is the portal to the infinite complexity of what it is to be human.

\section{Conclusion}

In the change room, that often sterile space comprised of generic and precise rows of lockers and benches, the revealing of the naked body may make me, under the eyes of the onlooker, into an aesthetic object. This can be a Sartrean experience of feeling robbed of my subjectivity, or it can be experienced positively as though under the admiring gaze of the other who sees in me my womanhood (or humanity). Perhaps it is not only one's womanhood that the naked body reveals, but also the contingency of one's unique being.

However, the women's change room environment does little to acknowledge the uniqueness of each body, or, of each woman. This analysis does not reveal or explicitly explore how the adolescent body, the pregnant body, the aging body, the "sick" body, the dis/abled body, the queer body or the racialized body might experience this space. If, optimistically we consider that the body, in its continuously moving, shifting form, can evade such stark categorization, then we must also remember that the body always encounters and exists within spaces that seek to contain and manage it. The body is always subjected to dominant ways in which the body is framed and understood.. Therefore, the body's experiences must always be considered within the unique spaces it inhabits. The design of spaces and settings occupied by bodies must be mindful of the needs of different bodies since they are neither fixed organic entities nor mere social constructions. They are at once a social and material force that constantly shape and are shaped by the physical and social environment around them.

\section{References}

Berger, J. (1972). Ways of Seeing. London: Penguin Books.

Bordo, S. (1993). Unbearable weight: Feminism, western culture, and the body. Berkeley, CA: University of California Press.

Butler, J. (1990). Gender trouble: Feminism and the subversion of identity. New York, NY: Routledge.

Crossley, N. (2004). The circuit trainer's habitus: Reflexive body techniques and the sociality of the workout. Body and Society, 10. 37-69. 
Dworkin, S.L. (2003). A woman's place is in the...cardiovascular room? Gender relations, the body and the gym. In A. Bolin \& J. Granskog (Eds.), Athletic intruders: Ethnographic research on women, culture, and exercise (pp. 131-158). New York, NY: SUNY Press.

Haravon Collins, L. (2002). Working out the contradictions: Feminism and aerobics. Journal of Sport and Social Issues, 26, 85-109.

Foucault, M. (1995). Discipline and punish: The birth of the prison [Surveiller et punir.] (2nd ed.). New York, NY: Vintage Books.

Fusco, C. (2006). Inscribing healthification: Governance, risk, surveillance and the subjects and spaces of fitness and health. Health \& Place, 12, 65-78.

Gard, M., \& Wright, J. (2005). The obesity epidemic. New York, NY: Routledge.

Grosz, E. (1994). Volatile bodies: Toward a corporeal feminism. Bloomington, IN: Indiana University Press.

Katula, J.A., McAuley, E., Mihalko, S. L., \& Bane, S. (1998). Mirror, mirror on the wall ... exercise environment influences on self-efficacy. Journal of Social Behavior and Personality, 13, 319-332.

Levinas, E. (2000). Totality and infinity: An essay on exteriority (A. Lingis, Trans.). Pittsburgh, PA: Duquesne University Press.

Martin-Ginis, K. A., Jung, M., \& Gauvin, L. (2003). To see or not to see: The effects of exercising in mirrored environments on sedentary women's feeling states and self-efficacy. Health Psychology, 22, 354-361.

Markula, P. (1995). Firm but shapely, fit but sexy, strong but thin: The postmodern aerobicizing female bodies. Sociology of Sport Journal, 12, 424-453.

McDermott, L. (2000). A qualitative assessment of the significance of body perception to women's physical activity experiences: Revisiting discussions of physicality. Sociology of Sport Journal, 17, 331-363.

Merleau-Ponty, M. (1962). Phenomenology of perception (C. Smith, Trans.). London: Routledge.

Prichard, I., \& Tiggemann, M. (2005). Objectification in fitness centers: Self-objectification, body dissatisfaction, and disordered eating in aerobic instructors and aerobic participants, Sex Roles. 53, 19-28. 
Prichard, I., \& Tiggemann, M. (2005b). Self-objectification, body image and reasons for exercise. Proceedings of the 40th APS Annual Conference (pp. 253-257). Melbourne, Australia: The Australian Psychological Society.

Sartre, Jean Paul (1956). Being and nothingness: An essay on phenomenological ontology. New York, NY: Philosophical Library.

Shilling, C. (2003). The body and social theory (2nd ed.). London: Sage.

Van den Berg, J.H. (1964). The significance of human movement. Philosophy and Phenomenological Research, 13, 159-183.

Van den Berg, J.H. (1974). Divided existence and complex society. Pittsburgh, PA: Duquesne University Press.

Van Manen, M. (1997). Researching lived experience: Human science for an action sensitive pedagogy (2nd ed.). London, ON: Althouse Press.

Van Manen, M. (2007). Phenomenology of practice. Phenomenology \& Practice, 1, 11-30.

Van Manen, M., \& Adams, C.A. (2010). Phenomenology. International Encyclopedia of Education, 6, 449-455.

Walton, V.R., \& Finkenberg, M.E. (2002). Female anxiety about social and exercise setting. Perceptual and Motor Skills, 94 700-702. 